13.3

\title{
Электрохимическая аморфизация как метод повышения скоростных характеристик кристаллических кремниевых анодов для литий-ионных аккумуляторов
}

\author{
(C) Г.В. Ли, Е.В. Астрова , А.М. Румянцев \\ Физико-технический институт им. А.Ф. Иоффре РАН, Санкт-Петербург, Россия \\ 『 E-mail: east@mail.ioffe.ru
}

Поступило в Редакцию 3 июля 2019г.

В окончательной редакции 22 июля 2019 г.

Принято к публикации 23 июля 2019г.

\begin{abstract}
Исследованы аноды, изготовленные из макропористого кремния. Гальваностатические циклические испытания, проведенные в полуячейкаX c Li-противоэлектродом в режиме ограничения зарядной емкости величиной $Q_{1}=1000 \mathrm{~mA} \cdot \mathrm{h} / \mathrm{g}$, показали, что включение в программу испытаний модифицирующего цикла с увеличенным временем электрохимического литирования позволяет поднять скорость заряда/разряда при возвращении к исходному режиму. Для интерпретации полученных результатов привлекается двухфазная модель с резкой границей $a-\mathrm{Li} x \mathrm{Si} / c-\mathrm{Si}$. Происходящее при модифицирующем цикле внедрение большего количества лития приводит к увеличению толщины аморфного слоя, в пределах которого на последующих циклах внедрение и экстракция лития происходят с большей скоростью.
\end{abstract}

Ключевые слова: литий-ионные аккумуляторы, кремниевые аноды, макропористый кремний, скоростные характеристики, гальваностатические циклические испытания.

DOI: 10.21883/PJTF.2019.22.48642.17962

Аноды на основе кремния перспективны для использования в аккумуляторах нового поколения, так как способны образовывать сплавы $\mathrm{Li}_{x} \mathrm{Si}$ с высоким содержанием лития и обеспечивать максимальную теоретическую емкость $4200 \mathrm{~mA} \cdot \mathrm{h} / \mathrm{g}$. Однако при внедрении лития кремний значительно увеличивается в объеме, что приводит к появлению больших механических напряжений и разрушению анода. Деградацию, связанную с разрушением, удается подавить за счет использования наноразмерных структур и ограничения количества внедряемого лития $[1,2]$. Скорость диффузии $\mathrm{Li}$ как в кристаллический $(c-\mathrm{Si})$, так и в аморфный $(a-\mathrm{Si})$ кремний при комнатной температуре невелика (в аморфном $\mathrm{Si}$ она выше [3]), что считается причиной, ограничивающей быстродействие литий-ионных аккумуляторов с

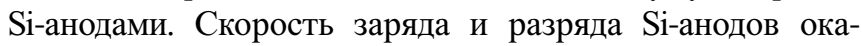
зывается намного ниже, чем углеродных, что не позволяет работать при больших мощностях. Кремниевые наноструктуры в виде проволок, плоских стенок или цилиндрических макропор часто получают из монокристаллического кремния с помощью электрохимического, реактивно-ионного или каталитического (metal-assisted) травления. В случае кремниевых электродов образование на поверхности пленки твердофазного электролита SEI (solid electrolyte interface) приводит на первых циклах к значительным необратимым потерям заряда, уменьшая тем самым полную емкость литий-ионной батареи. Для компенсации потерь активного лития используется предварительное литирование [4], которое заключается в электрохимическом или химическом внедрении лития в отрицательный электрод.
В отличие от этого традиционного прелитирования в настоящей работе мы исследуем электрохимические свойства структуры после модифицирующего цикла, который предусматривает как внедрение, так и обратимую экстракцию лития. На примере кристаллической Si-cтруктуры с глубокими цилиндрическими макропорами мы показываем, что такая подготовка приводит к значительному повышению максимальной скорости заряда/разряда, но одновременно ускоряет процесс деградации электрода.

Аноды изготавливались из мембраны с самоорганизующимися цилиндрическими макропорами, полученными с помощью фотоэлектрохимического травления пластины монокристаллического Si (детали технологии см. в $[5,6])$. Кремниевый пористый слой в структуpe с медным токосъемным контактом имел толщину $l=65 \mu \mathrm{m}$ и пористость $p=61 \%$. Среднее расстояние между порами составило $a=1.60 \mu \mathrm{m}$, а средний диаметр пор $d=1.32 \mu \mathrm{m}$. Полагая, что поры образуют гексагональную решетку, можно посчитать их число на $1 \mathrm{~cm}^{2}$ видимой площади пластины: $4.5 \cdot 10^{7}$. Умножение этого числа на площадь поверхности одной макропоры $s=\pi d l=2.7 \cdot 10^{-6} \mathrm{~cm}^{2}$ показывает, что реальная поверхность $A$ в 120 раз больше, чем видимая. Разность $a-d=280 \mathrm{~nm}$ определяет наименьшую толщину стенки в плоскости, параллельной поверхности пластины. Далее из такой мембраны было вырезано три электрода меньшей площади.

Полученные аноды собирались в двухэлектродные дисковые корпуса CR2032, где вторым электродом служил металлический литий. Полуячейки подвергались 

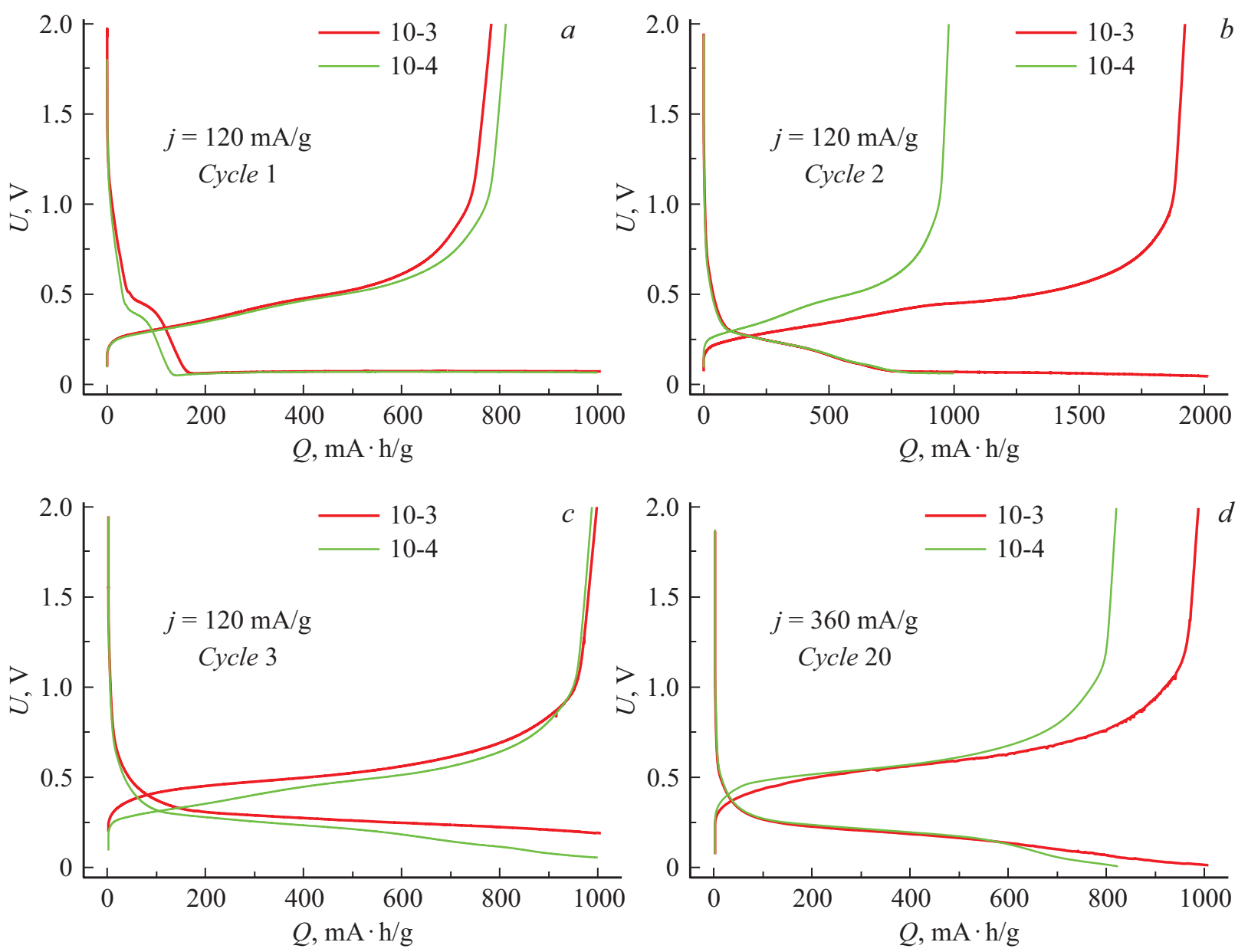

Рис. 1. Зарядно-разрядные кривые для контрольного (10-4) и модифицированного (10-3) образцов. Циклы 1 (a), 2 (b) и 3 (c) проводились при плотности тока $j=120 \mathrm{~mA} / \mathrm{g}$, цикл 20 - при $j=360 \mathrm{~mA} / \mathrm{g}(d)$. На цикле 2 для образца 10-3 время заряда было увеличено в 2 раза.

циклическим испытаниям в гальваностатическом режиме на стенде CT3008W-5V10mA (Neware). В качестве электролита использовался коммерческий продукт TC-E918 (Tinci, КНP), представляющий собой $1 \mathrm{M}$ раствор $\mathrm{LiPF}_{6}$ в смеси EC/PC/DEC/EMC (этиленкарбонат, пропиленкарбонат, диэтилкарбонат, этилметилкарбонат). Заряд (внедрение лития) ограничивали величиной удельной емкости $Q_{1}=1000 \mathrm{~mA} \cdot \mathrm{h} / \mathrm{g}$ и потенциалом относительно лития $U_{\min }=10 \mathrm{mV}$, разряд только напряжением $2 \mathrm{~V}$. Плотность тока варьировалась в диапазоне $120-360 \mathrm{~mA} / \mathrm{g}$, что соответствовало заданному времени литирования $8.33-2.78 \mathrm{~h}$. При заряде срабатывало ограничение либо по емкости, либо по напряжению $10 \mathrm{mV}$. В последнем случае реальное время заряда оказывалось меньше, чем заданное.

Рассмотрим зарядно-разрядные кривые двух образцов: 10-3 и 10-4, вырезанных из одной мембраны (рис. 1). При заряде происходит внедрение Li в кристаллическую стенку кремниевой структуры, что соответствует горизонтальному плато на зарядной кривой (рис. $1, a$ ). Кривые цикла 1 для обоих образцов практически совпадают друг с другом. Ступенька в области $400 \mathrm{mV}$ связана с формированием пленки SEI.

На цикле 2 (рис. $1, b)$ для одного из образцов (10-3) время литирования было увеличено в 2 раза, что при постоянстве зарядного тока соответствовало повышению зарядной емкости до величины $Q_{2}=2000 \mathrm{~mA} \cdot \mathrm{h} / \mathrm{g}$. При этом он подвергся модификации, повлиявшей на его электрохимические характеристики. Для второго (контрольного) образца 10-4 время осталось прежним $(t=8.33 \mathrm{~h})$.

Далее оба образца испытывались в одинаковом (номинальном) режиме с ограничением зарядной емкости $Q_{1}=1000 \mathrm{~mA} \cdot \mathrm{h} / \mathrm{g}$ при токе $j=120 \mathrm{~mA} / \mathrm{g}$. На цикле 3 их зарядно-разрядные кривые стали различаться. Из рис. 1, $c$ видно, что все кривые - как зарядные, так и разрядные - для модифицированного образца 10-3 располагаются выше по напряжению, чем для контрольного. Это свидетельствует о том, что концентрация $\mathrm{Li}$ на его поверхности ниже. Для обоих образцов начиная с цикла 10 была увеличена плотность тока заряда и разряда. Ток увеличивался в $1.5-3$ раза ступенчато через 
Напряжение на контрольном и модифицированном электродах в конце гальваностатического литирования при разных токах и соответствующая ему величина внедренного заряда

\begin{tabular}{c|c|c|c|c|c}
\hline \multirow{2}{*}{$\begin{array}{c}\text { Номер } \\
\text { цикла }\end{array}$} & \multirow{2}{*}{$j, \mathrm{~mA} / \mathrm{g}$} & \multicolumn{2}{|c|}{ Контрольный образец 10-4 } & \multicolumn{2}{|c}{ Модифицированный образец 10-3 } \\
\cline { 2 - 5 } & & $U, \mathrm{mV}$ & $Q, \mathrm{~mA} \cdot \mathrm{h} / \mathrm{g}$ & $U, \mathrm{mV}$ & $Q, \mathrm{~mA} \cdot \mathrm{h} / \mathrm{g}$ \\
\hline 1 & 120 & 70 & 1000 & 70 & 1000 \\
2 & 120 & 63 & 1000 & 50 & 2000 \\
3 & 120 & 56 & 1000 & 190 & 1000 \\
20 & 360 & 10 & 800 & 19 & 1000
\end{tabular}

каждые три цикла. Таким образом, на зависимостях разрядной емкости от номера цикла $N$ (рис. 2) имеются участки, соответствующие $j=120,180,240,300$ и $360 \mathrm{~mA} / \mathrm{g}$. Видно, что модифицированный образец 10-3 не снижает свою разрядную емкость при повышении тока до $360 \mathrm{~mA} / \mathrm{g}$, в то время как для контрольного образца 10-4 наблюдается падение емкости на 21\%. Следовательно, модифицированный образец может заряжаться со скоростью, в 3 раза большей, чем контрольный. На рис. 1, $d$ показаны зарядно-разрядные кривые, полученные при токе $360 \mathrm{~mA} / \mathrm{g}$ (цикл 20), из которых хорошо видно, что в контрольный образец не может внедриться заданное количество лития и время полуцикла литирования сокращается. Соответственно разрядная емкость тоже падает. Следует обратить внимание на то, что для контрольного образца $10-4$ при токе $180 \mathrm{~mA} / \mathrm{g}$ в течение трех циклов $(N=10-12)$ не наблюдалось снижения емкости, а при увеличении числа циклов начиная с $N=30$ произошло падение емкости на $15 \%$.

Начиная с цикла 52 оба образца (10-3 и 10-4) были вновь переведены в номинальный режим $(j=120 \mathrm{~mA} / \mathrm{g}$, $\left.Q=1000 \mathrm{~mA} \cdot \mathrm{h} / \mathrm{g}, U_{\min }=10 \mathrm{mV}\right)$. Циклическим испытаниям подвергся еще один электрод 1-7, вырезанный из той же мембраны и модифицированный путем внедрения и экстракции еще большего, чем для образца

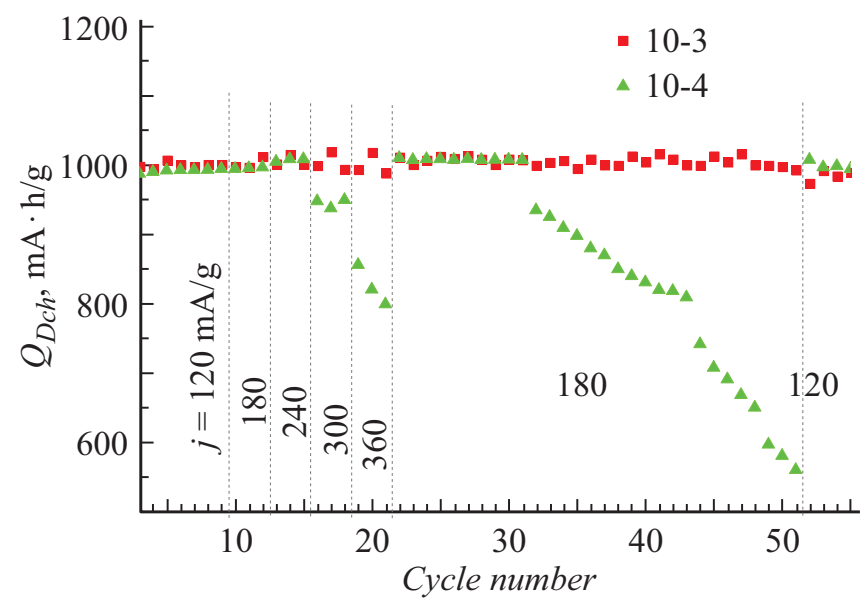

Рис. 2. Зависимость разрядной емкости от номера цикла для модифицированного (10-3) и контрольного (10-4) образцов при испытаниях на разных токах, указанных на рисунке.
10-3, заряда $Q_{3}=2444 \mathrm{~mA} \cdot \mathrm{h} / \mathrm{g}$. Сравнение циклического времени жизни для трех образцов показало, что падение разрядной емкости на $20 \%$ для контрольного образца происходит после цикла 220, в то время как для модифицированных образцов 10-3 и 1-7 - после циклов 85 и 43 соответственно. Таким образом, модификация, проведенная во время цикла 2, приводит к сокращению циклического времени жизни.

Известно, что при электрохимическом внедрении лития в кристаллический кремний образуются аморфные сплавы $\mathrm{Li}_{x} \mathrm{Si}$ и после экстракции лития $\mathrm{Si}$ остается аморфным [7-9]. Как было показано в [10,11], кристаллические кремниевые микроструктуры способны работать в режиме, когда литий проникает не на всю глубину $\mathrm{Si}$-частиц, т.е. при циклировании сохраняется граница между аморфным и кристаллическим кремнием. Первые циклы литирования и делитирования играют важную роль для последующего поведения электродов, так как определяют, какое количество $c$-Si может быть преобразовано в аморфный. Концентрация лития на поверхности электрода, граничащей с электролитом, и его равновесный потенциал связаны между собой упрощенным выражением для уравнения Нернста [12]:

$$
E=E_{0}-(R T / n F) \ln C,
$$

где $E_{0}-$ стандартный электродный потенциал, $R-$ газовая постоянная, $T$ - абсолютная температура, $n-$ число электронов, $F-$ число Фарадея, $C-$ концентрация лития в сплаве на поверхности электрода. При протекании тока потенциал уже нельзя считать равновесным, однако при сравнении образцов, которые испытываются при одинаковой плотности тока, можно, как и для равновесных условий, полагать, что чем выше концентрация Li, тем ниже электродный потенциал. Экспериментально найденные значения напряжения на электроде в конце каждого цикла литирования приведены в таблице.

Кинетика литирования кристаллического кремния подробно рассмотрена в работе [13]. Согласно предложенной авторами модели, скорость литирования зависит от соотношения между тремя скоростями: 1) реакции восстановления ионов лития на интерфейсе между электродом и электролитом; 2) диффузии Li в аморфном литированном слое; 3) химической реакции на границе 
$a-\mathrm{Li}_{x} \mathrm{Si} / c-\mathrm{Si}$. При внедрении лития в гальваностатическом режиме первый процесс при реально используемых токах обычно протекает быстро. Для двух других были сформулированы следующие критерии того, какой из этих процессов является определяющим. Если при литировании потенциал электрода со временем падает, то наиболее медленным процессом является диффузия (малый $\left.D_{\mathrm{Li}}\right)$. В том случае, когда $D_{\mathrm{Li}}$ велик, а скорость реакции на границе с $c$-Si мала, на зарядной кривой наблюдается плато ( $U=$ const). Авторы приходят к выводу, что чаще всего литирование кристаллического кремния ограничивается скоростью реакции на границе $a-\mathrm{Li}_{x} \mathrm{Si} / c-\mathrm{Si}$. Разная скорость этой реакции для различных кристаллографических плоскостей обусловливает анизотропию при литировании монокристаллического кремния [14-16].

Поскольку на зарядных кривых на рис. $1, a$ и $b$ имеется плато, можно заключить, что лимитирующим (наиболее медленным процессом) является реакция на границе с $c$-Si. При этом в режиме постоянного тока толщина литированного слоя со временем возрастает, а концентрация лития $C$ на поверхности электрода остается практически неизменной. Оценим толщину литированного кремния. По закону Фарадея количество молей лития, внедряемых в кремний, $m_{\mathrm{Li}}=J t / F$, где $J-$ плотность тока, $t$ - время литирования. Количество вступившего в реакцию $\mathrm{Si} m_{\mathrm{Si}}=m_{\mathrm{Li}} / x$, что соответствует толщине

$$
d_{\mathrm{Si}}=J t \Omega / x F
$$

где $\Omega=12.1 \mathrm{~cm}^{3} / \mathrm{mol}$ - молярный объем кремния. Истинная плотность тока $J$ может быть найдена исходя из площади поверхности пор. Для номинального режима тестирования при $j=120 \mathrm{~mA} / \mathrm{g}$ (плотность тока на единицу видимой площади электрода $j_{s}=0.7 \mathrm{~mA} / \mathrm{cm}^{2}$ ) истинная плотность тока $J=j_{s} / A=5.8 \mu \mathrm{A} / \mathrm{cm}^{2}$. Тогда, принимая $x=3.75$, можно получить, что за время $t=8.33 \mathrm{~h}$ толщина аморфного кремния составит $d_{\mathrm{Si}}=58 \mathrm{~nm}$, а в случае модифицирующего цикла, когда $t=16.7 \mathrm{~h}, d_{\mathrm{Si}}=116 \mathrm{~nm}$. В обоих случаях эти значения меньше половины толщины кремниевой стенки. Таким образом, эта оценка подтверждает, что при циклировании сохраняется двухфазная структура с резкой границей $a-\mathrm{Li}_{x} \mathrm{Si} / c-\mathrm{Si}$.

На рис. 3 приведено схематическое представление этой двухфазной структуры, где по оси абсцисс отложена координата в направлении движения литированного фронта $z$, а по оси ординат - концентрация лития; $z=0$ соответствует границе кремния с электролитом, $z_{1}$ - граница аморфного слоя для контрольного образца, $z_{2}$ - для модифицированного. На границе с $c$-Si концентрация лития резко падает. Площадь полученного прямоугольника пропорциональна внедренному количеству электричества $Q_{1}=1000 \mathrm{~mA} \cdot \mathrm{h} / \mathrm{g}$. В процессе модификации образца 10-3 на цикле 2 литированный фронт сдвигается в глубь Si-стенки, а площадь полученного

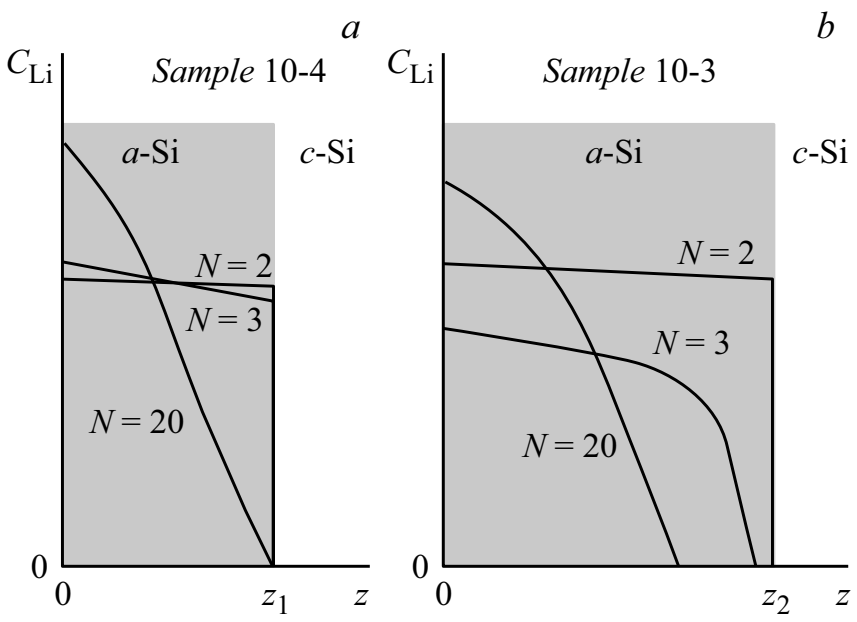

Рис. 3. Схема, показывающая распределение лития в кремниевых электродах на разных циклах N. $a$ - для контрольного образца $10-4, b$ - для модифицированного образца 10-3. Плотность тока заряда и внедренная емкость приведены в таблице.

прямоугольника в соответствии с внедренным количеством лития возрастает в 2 раза до $Q_{2}=2000 \mathrm{~mA} \cdot \mathrm{h} / \mathrm{g}$ (рис. $3, b, N=2$ ). Свойства аморфного слоя после модифицирующего цикла в области $z<z_{1}$ могут отличаться от свойств того же слоя в контрольном образце. Например, коэффициент диффузии может увеличиться за счет появления дополнительных механических напряжений и деформации решетки [17]. Однако при дальнейшем рассмотрении профилей распределения лития мы этот фактор учитывать не будем.

В номинальном режиме на цикле 3 и последующих в образце 10-3 литированный слой может свободно распространяться, оставаясь в пределах аморфной фазы (рис. $3, b, N=3$ ). Он проникает на бо́льшую глубину, чем в случае контрольного образца 10-4. Концентрация лития на поверхности уменьшается, и потенциал повышается до $190 \mathrm{mV}$. Из зарядных и разрядных кривых для цикла 3 (рис. $1, c$ ) следует, что концентрация лития в контрольном образце вблизи поверхности все время остается выше, чем в модифицированном, из-за наличия блокирующей границы $z_{1}$. При этом площадь под кривыми $C(z)$ для цикла 3 на рис. $3, a$ и $b$ остается неизменной, пропорциональной $Q_{1}$. Следует отметить, что зарядные кривые на рис. 1, с для обоих образцов становятся наклонными, это свидетельствует о том, что концентрация Li на поверхности со временем возрастает, т.е. в процессе накопления заряда уже не происходит смещения границы $a-\mathrm{Li}_{x} \mathrm{Si} / c-\mathrm{Si}$ в глубь кристаллической стенки макропористой структуры, и лимитирующим процессом становится диффузия в аморфной фазе.

Рассмотрим, что происходит при увеличении плотности тока до $360 \mathrm{~mA} / \mathrm{g}$ (цикл 20). Как следует из рис. $1, d$ и таблицы, потенциал в конце заряда для контрольного образца $(10 \mathrm{mV})$ ниже, чем для модифицированного 
$(19 \mathrm{mV})$, т.е. вблизи поверхности концентрация лития выше. Как видно из профиля концентрации Li (рис. 3, b, $N=20$ ), при повышении тока в модифицированном образце литий проникает на меньшую глубину, чем в номинальном режиме (рис. $3, b, N=3$ ), так как при сохранении заряда $Q_{1}$ время сокращается в 3 раза. Литированный слой по-прежнему остается в пределах аморфной фазы при $z<z_{2}$. Для контрольного образца диффузионное проникновение примеси имеет другие граничные условия за счет блокирующего интерфейса $a-\mathrm{Li}_{x} \mathrm{Si} / c-\mathrm{Si}$. Это приводит к тому, что концентрация на поверхности образца 10-4 увеличивается по сравнению с таковой для образца 10-3, потенциал снижается до $10 \mathrm{mV}$ уже при $Q=800 \mathrm{~mA} \cdot \mathrm{h} / \mathrm{g}$, т.е. в этом случае внедренное количество электричества $Q<Q_{1}$ (рис. $3, a, N=20$ ).

Снижение циклического времени жизни модифицированных электродов по сравнению с контрольным указывает на то, что внедрение большего количества лития не оставляет структуру материала неизменной. По-видимому, из-за более высоких механических напряжений в ней возникают дополнительные дефекты, которых тем больше, чем выше внедренная емкость. Эти дефекты, возможно в виде трещин, распространяются по структуре в процессе продолжающегося циклирования и приводят к более быстрой деградации. Таким образом, выбирая режим модификации, следует соблюдать компромисс между скоростными характеристиками и циклическим временем жизни электрода.

В ходе проделанной работы установлено, что аморфизация кремния, происходящая в процессе его электрохимического литирования на бо́льшую глубину, чем при номинальном режиме циклирования, позволяет повысить скорость работы кристаллических микроструктурных электродов из $\mathrm{Si}$. Исследовано влияние такой электрохимической аморфизации на характеристики макропористых анодов и показано, что контроль за двухфазной структурой с помощью модифицирующего цикла заряда/разряда дает возможность повысить рабочий ток, сохраняя в разумных пределах циклическое время жизни электродов.

\section{Финансирование работы}

Работа выполнена в рамках государственного задания ФТИ им. А.Ф. Иоффе в области фундаментальных научных исследований.

\section{Конфликт интересов}

Авторы заявляют, что у них нет конфликта интересов.

\section{Список литературы}

[1] Zhang S., Zhao K., Zhu T., Li J. // Prog. Mater. Sci. 2017. V. 89. P. 479-521.

[2] Du F.-H., Wang K.-X., Chen J.-Sh. // J. Mater. Chem. A. 2016. V. 4. P. $32-50$.
[3] Федоров А.С., Попов З.И., Кузубов А.А., Овчинников С.Г. // Письма в ЖЭТФ. 2012. Т. 95. В. 3. С. 159-163.

[4] Holtstiege F., Bärmann P., Nölle R., Winter M., Placke T. // Batteries. 2018. V. 4. N 1. P. 4.

[5] Astrova E.V., Preobrazhenskiy N.E., Lihachev A.I., Li G.V. // J. Micromech. Microeng. 2018. V. 28. N 11. P. 115014.

[6] Ли Г.В., Астрова Е.В., Румянщев А.М., Воронков В.Б., Парфеньева А.В., Толмачев В.А., Кулова Т.Л., Скундин A.M. // Электрохимия. 2015. Т. 51. № 10. С. 1020-1029.

[7] Li H., Huang X., Chen L., Zhou G., Zhang Z., Yu D., Mo Y.J., Pei N. // Solid State Ion. 2000. V. 135. N 1-4. P. 181-191.

[8] Obrovac M.N., Christensen L. // Electrochem. Solid-State Lett. 2004. V. 7. P. A93-A96.

[9] Zhang W.-J. // J. Power Sources. 2011. V. 196. N 3. P. $877-$ 885.

[10] Obrovac M.N., Krause L.J. // J. Electrochem. Soc. 2007. V. 154. N 2. P. A103-A108.

[11] Lee G., Schweizer S.L., Wehrspohn R.B. // Appl. Phys. A. 2014. V. 117. N 3. P. 973-979.

[12] Чуриков А.В. Математика диффузии в приложении к литиевым электрохимическим системам. М.: Наука, 2015. C. 48.

[13] Pharr M., Zhao K., Wang X., Suo Z., Vlassak J.J. // Nano Lett. 2012. V. 12. N 9. P. 5039-5047.

[14] Lee S.W., McDowell M.T., Choi J.W., Cui Y. // Nano Lett. 2011. V. 11. N 7. P. 3034-3039.

[15] Goldman J.L., Long B.R., Gewirth A.A., Nuzzo R.G. // Adv. Funct. Mater. 2011. V. 21. N 13. P. 2412-2422.

[16] Астрова Е.В., Румянщев А.М., Ли Г.В., Нащекин А.В., Казанцев Д.Ю., Бер Б.Я., Жданов В.В. // ФТП. 2016. Т. 50. B. 7. C. $979-986$.

[17] Попов З.И., Федоров А.С., Козубов А.А., Кохсевникова T.A. // ЖСХ. 2011. Т. 52. № 5. С. 891-899. 